\title{
Genetic diversity in Egyptian populations of Achillea santolina using morphological traits and ISSR markers
}

\author{
${ }^{1}$ Abdelfattah Badr, ${ }^{2}$ Hanan I. Sayed Ahmed, ${ }^{2}$ Marwa \\ Hamouda and ${ }^{2}$ Eman A. El-Khateeb \\ ${ }^{1}$ Botany and Microbiology Department, Faculty of Science, Helwan University, \\ 11790 Cairo, Egypt) \\ ${ }^{2}$ Botany Department, Faculty of Science, Tanta University, 31527 Tanta, Egypt \\ Corresponding author: abadr_tanta@hotmail.com
}

Abdelfattah Badr, Hanan I. Sayed Ahmed, Marwa Hamouda and Eman A. El-Khateeb, 2014. Genetic diversity in Egyptian populations of Achillea santolina using morphological traits and ISSR markers. Taeckholmia 34: 49-65.

\begin{abstract}
$\boldsymbol{V}$ ariation in 27 morphological traits and 105ISSR markers were used to elucidate the genetic diversity innine populations of Achilleasantolina in Egypt. Two populations (Coded S8 and S9)which grow in El-Hammam and Burg El-Arab,65 and 40kmwest of Alexandria respectively were clearly differentiated from other populations growing further westto $150 \mathrm{Km}$ west of Matrouh City towards the Libyan borders on the Mediterranean coast. The ISSR data clearly distinguished a population coded S1 which grows 140 west of Matrouh City $(250 \mathrm{~km}$ west of Alexandria). The morphological traits showed much closer resemblance among populations compared to ISSR polymorphism but agree with ISSR data in supporting the idea of a possible gene flow in the populations of $A$. santolinagrowing in close locations and limited gene flow among populations distributed in geographically distantlocations. Knowledge of the amount and distribution of genetic variability reported here is helpful for further assessment of genetic resources and provides information for authentication of Egyptian material and conservation of A. santolina in Egypt. The data reported here is also potentially useful in future efforts to restore degraded ecosystems in the semi-arid regions of the country.
\end{abstract}

Key words: Achilleasantolina, Genetic diversity, Egypt, ISSR markers, Conservation.

$\overline{\text { Received } 14 \text { August 2014, }}$ Accepted 6 September 2014 
Abdelfattah Badr et al.

\section{Introduction}

Achilleasantolina L. (Asteraceae)grows in calcareous and sandy soils in the Mediterranean coastal strip of Egypt particularly from the border of Libya to Alexandria. Its world-wide distribution extends to North Africa, Middle East and more easternto Afghanistan and Pakistan (Boulos 2002). The plant is a perennial growing to $0.3 \mathrm{~m}(1 \mathrm{ft})$, and the flowers are hermaphrodite and pollinated by insects(Boulos2002). Achilleasantolina is used for anti-inflammatory purposes, analgesic, antipyretic and treatment of diabetes (Al-Hindawi, et al.,1989).Essential oils obtained by steam distillation from the flower, leaf and stem of A. santolina revealed 54 volatile components (Aboutabl, et. al.,1986 andEl-Shazly, et al., 2004). Like many other wild medicinal plants,A. santolina in Egypt is exposed to serious threats due to natural drougth and heavy human impacts such as uncontrolled tourism, overgrazing and uncontrolled collection, mining and quarrying (Badr, et. al.,2014). Achilleasantolinais an important component of genetic resources in the Egyptian floraand is potentially usable to restore degraded ecosystems in the semi-arid regions of the country.

Effective conservation of a vulnerable species depends largely on the knowledge of genetic variation (Torre et al., 2008). Knowledge of the amount and distribution of genetic variability is also helpful in managing plant genetic resources and provides information for designing protocols for their conservation (Bretting\&Wilrlechner, 1995 andTorre et. al., 2008). Morphological characterization is the first step in description and classification of genetic variation and is among the oldest markers used in the evaluation of genetic variability. It has been described for characters controlled by a single or multiple gene systems; the greater of gene loci number that determine a trait, the more continuous the variation will be (Ayala, 1982).

In the last two decades, DNA markers have been developed as reliable approaches for estimating genetic diversity in plants. These markers aim at revealing potentially useful variability by screening a fraction of all possible loci of the genome (Karp et al., 1996; 1998). DNA markers are reliable because the genetic information is unique for each species and is independent of age, physiological conditions and environmental factors (Kalpanaet al., 2004). The information derived from the DNA further provide great number of characters (markers) that are easy to observe, score and analyze independent of the growth stage, season, location, and 
agricultural practice (Lombard et. al., 2001). Combination of morphological variations and molecular markers as well as other data is more comprehensive and meaningful for the documentation of genetic diversity for conservation of biodiversity (Badr, 2008).

The inter-simple sequence repeats (ISSR) developed by Zietkiewiczet. al. (1994) accesses variation in the numerous microsatellite regions dispersed throughout the various genomes (particularly the nuclear genome) and circumvents the challenge of characterizing individual loci that other molecular approaches require. The ISSR has been used with success to identify and determine relationships at the species, population, and cultivar levels in many plant species, including several aromatic and medicinal plants (Nanet. al., 2003 andFracaroet. al., 2005; Mohsen and Ali, 2008; Manica-Cattaniet. al. 2009; Tharachandet al.; 2012 andBadret. al., 2012). Limited reports on the genetic relationships among populations ofAchillea species have been published (Wallneret. al., 1996; Morsy, 2007 andRahimmaleket. al., 2009). In this study, we use morphological variation and polymorphism of ISSR markers to investigate the genetic variation and differentiation of selected population of A. santolina in Egypt.

\section{Material and methods \\ Plant material}

Samples of nine populations of $A$. santolina L. (S1-S9) were collected from their natural habitats as mature flowering plants, through 2009 to 2012, from different localities in the Mediterranean coastal region of Egypt (Table 1; Fig.1). Eighteen quantitative morphological traits were measured and the states of ten qualitative traits were scored for 5-10 samples for each population. The average value of each quantitative trait \pm standard deviation was calculated and the state of the qualitative traits was determined based on the deacription of these traits with reference to Boulos (2002).Voucher specimens of all populations have been deposited at the Herbarium of Botany Department(TANE), Faculty of Science, Tanta University, Tanta, Egypt.

\section{ISSR finger-printing}

The ISSR procedure used in the present study is based on the method described by Doganet. al. (2007).In total, 17 ISSR primers (Operon Nippon EGT CO. LTD.) were screened for the production of polymorphic products. The sequence of the primers and their properties are mentioned in Table 
2.For ISSR fingerprinting, a total of $25 \mu 1$ reaction mix was prepared (12.5 $\mu 1$ Maxima Hot Start PCR Master Mix, $0.5 \mu 1$ of the primer, $0.5 \mu 1$ templates DNA of different populations and nuclease-free water to 25 $\mu$ l.Amplification conditions were optimized using a gradient thermal cycler (Biometera Uno thermal cycler, Germany) using a standardized PCR program with initial denaturation at $94^{\circ} \mathrm{C}$ for $5 \mathrm{~min}$, followed by 35 cycles of denaturation for $1 \mathrm{~min}$ at $94^{\circ} \mathrm{C}$, annealing according to each primer Tm5 for $45 \mathrm{sec}$, and $2 \mathrm{~min}$ at $72^{\circ} \mathrm{C}$ for extension and a final extension of $5 \mathrm{~min}$ at $72^{\circ} \mathrm{C}$ and then at $4^{\circ} \mathrm{C}$ till removal of PCR tubes within 12 hours.

The amplification products were separated by mixing $10 \mu \mathrm{l}$ of the PCRproducts of each primer and $2 \mu \mathrm{l}$ and the $12 \mu \mathrm{lmix}$ was loaded into the agarose wells. Electrophoresis was made in $1.5 \%$ agarose gel prepared in $0.5 \mathrm{X}$ TAE buffer at $70 \mathrm{~V}$ for $3 \mathrm{hr}$. The ISSR fingerprinting was visualized using a Gel Works 1D advanced gel documentation system (UVP, UK) and photographed under UV light. The size of each product (band) was estimated using $100 \mathrm{bp}$ DNA ladder (Fermentas) as a standard marker. Molecular size determination for ISSR fragments were calculated usingthe Lab Image SoftwareProgram version 2.7 produced by (KapelanGmbHCo, Germany)

\section{Data analysis}

The relationship among the examined populations of $A$. santolina was estimated based on the differences in both morphological traits and molecular fingerprintting. The morphological traits were given codes ranging between 0 and 3 . In the meantime, the clear, unambiguous and reproducible ISSR bands were considered for scoring. Each band was considered a single locus and scored as 1 for the presence and 0 for the absence.The Euclidean dissimilarity coefficient among populations was calculated according to Legendre and Legendre (1983)and genetic distance measures were performed using the Community Analysis Package Software Program (CAP) by Richard and Peter (2007). The CAP software was also used to construct genetic distance trees elucidating the relationships among the examined populations. For tree construction, the agglomerative cluster analysis method was used according to Ward (1963).

\section{Results}

Morphological variations in Achilleasantolinapopulations 
The measurements of the quantitative traits and description of qualitative traits in the populations of A. santolina are given in Table 3 . The state of qualitative traits was similar in all populations of $A$. santolinawhile considerable differences were evident in quantitative traits among the examined populations. The major differences are mainly between the populations S8 and S9 and most other populations in plant size as these populations have smaller plants. The plants of these two populations have more branches/plant $(8.33 \pm 4.16$ for $\mathrm{S} 8$ and $8.67 \pm 1.53$ for $\mathrm{S} 9$, more leaves/branch $(28.67 \pm 4.73$ for S8 and $24.33 \pm 1.53$ for S9). Meanwhile, the plants of $\mathrm{S} 1$ have smaller leaves (leaf length $=0.53 \pm 0.06 \mathrm{~cm}$ ), fewer numbers of florets per head $(20.67 \pm 0.58)$ and less weight of 100 seeds $(10.83 \pm 0.29 \mathrm{mg})$. Another noteworthy comment on the variation in morphological traits is the much lower vigor and lower germination percentage for the plants of S4, S5 and S6(Table 3).

\section{Genetic diversity based on variation in morphological variation}

The genetic distances among populations were found to be similar in all trees and a distance tree produced by the CAP software using the Ward method is shown in Figure2. The examined populations are divided as two main groups at a distance of 15.7 on the distance scale; one small which have twopopulation S8 from El-Hammam, $65 \mathrm{~km}$ west of Alexandria and S9 from Burg El-Arab, $40 \mathrm{~km}$ west of Alexandria (Fig. 1).While a large group comprising the seven other populations are differentiated into two clusters; cluster 1 is comprised of four population; S1 from Sidi-Barany, S2 from $50 \mathrm{Km}$ west of Matrouh City, S3 fromEl-Nigelaand S7 fromRaas-ElHekma. On the other hand cluster 2 comprised three population; S4 fromElNigela,S5 from El-Obeiyedin Matrouh City,and S6 from Samala.

\section{ISSR fingerprinting of Achilleasantolinapopulations}

Of the 17 primers used for ISSR fingerprinting inA.santolinapopulations only 13 primers produced stable and reproducible polymorphism in the generated DNA profiles of seven populations including seven primersthat produced polymorphism in all nine populations, examples of ISSR fingerprinting for seven primers are illustrated in Figure2A-G. A total of 105ISSR bands were scored; of these 58 bands were polymorphic, 32 monomorphic and 15 unique bands. The number of polymorphic bands and percentage of polymorphism in the ISSR profile of all primers are given in Table (2).These data indicates the existence of considerable polymorphism among the examined populations in the study area. 
Some bands were specific for certain populations; the population S1 has 8 unique bands; these bands have molecular size of $215 \mathrm{bp}$ in the profile of primer 17899 (Fig. 2C), 215 bp in primer HB-9 (Fig. 2D); 213bp and 850 bp in primer HB-10 (Fig. 2E), 995bp and 886 bp in primer HB-11 and 501 bpand 504bp in the profiles of HB-13and HB-14respectively (Fig. 2FandG). The population S4 also has three unique bands, with molecular size of 805bp, 728bp and $663 \mathrm{bp}$ in the profiles of primers HB-8, HB-9(Fig. 2D) and HB-12 respectively (Fig. 2E). The populations S3, S5, S7 and S9 have only one unique bandeach, these bands have molecular sizesof 825 bpin primer HB-8, 683bp in Primer HB-11, 1050 in primer 808 and 776 bp in primer 17898B (Fig. 2B) respectively.The data in Table (2)showed that the level of polymorphism revealed by all primers.

\section{Genetic distance based on polymorphism in ISSRfingerprinting.}

The genetic distances among populations was expressed by similar trees one tree is described in details here. The distance tree produced by the CAP software using the Ward method is shown in Figure (4). The examined populationsare divided into two main groups at a distance of 62.1 on the tree distance scale; one represented byS9from Burg El-Araband S8 from El Hammam;both grow in places near Alexandria.In the large group ofthe tree, thepopulation S1 from Sidi-Barany is clearly differentiated from the other six populations. These are divided into twoclusters; oneincludes S2, S3 and S7and the other includes S3, S4and S6; the S7 and S6 are clearly distinct identities from S2 and S3 and S4 and S5 respectively.

\section{Genetic relationship revealed by combined data molecular and morphology data.}

The genetic distance tree produced by the CAP software using the Ward method based on morphological and ISSR data was similar to the tree based on ISSR data. However, the examined populationswere divided into two groups at a distance of 77.8 on the distance scale; also in this tree the two populationsS8 and S9 were distinguished from the remaining populations. Thepopulation $\mathrm{S} 1$ was also differentiated whereas the remaining populations were dividedas two clusters; one comprising S2, S3 and S7 and the other S5, S4and S6. The two populations S7 and S6 are also distinct identities in this tree from $\mathrm{S} 2$ and $\mathrm{S} 3$ and $\mathrm{S} 4$ and $\mathrm{S} 5$ respectively. 


\section{Discussion}

Based on the differences in the quantitative traits, the two populations S8 and S9 were clearly separated from the other seven populations; these two populations havesmallerplantsize, plant crown width, internodes length compared to other populations. Also S8 and S9 have higher number of branchesandleaves, and highweight of 100 seeds and higher germination percentage andmore vigor than the other populations. Both populationsgrow in places near Alexandria (Fig.1). The morphological data also indicated that populations growing atclose locationsshare resemblance in some morphological traits, for example the two populations S4 and S5 have much lower vigor and germination percentage compared to other populations. Populations S7 growingeast of Matrouhcity hashigherleaf size than the other populations. Morphological trait measurements of $A$. santolina thus provide quantifying genetic variation related to genotype performance under the prevailing environments in the study area.This isconsistent with Sarkhoshet al. (2009) who reported that morphological characters often result in narrow morphological differences in the same species.

The grouping of A. santolina populations from the same geographical locations togethermay indicate the occurrence of frequent gene flow whereas the separation of populations from different locations, particularly population 1 and the two populations S8 and S9 support the idea of a limited gene flow due to fragmentation of the geographical range of A. santolina in the study area.The variation in A. santolina based on their geographical distributionis in agreement with Rahimmaleket al. (2009) who studied the genetic diversity of 57 Achillea accessions belonging to five species using AFLP markers and reported low genetic diversity in the germplasm of $A$. santolina(Farajpouret al., 2011) reported variation in the amount of essential oil and morphological traits in different genotypesof $A$. santolinafrom different provinces in Iran. These authors concludedthat such variation provides basic information for effective conservation of the examined accessions.

Population genetic diversity in a species is affected by a number of evolutionary factors including mating system, gene flow, seed dispersal, geographic range as well as natural selection (Hamrick and Godt, 1996). Representative population from the geographical range of the species can help to ensure conservation of co-adapted gene complexes (Beuselinckand Steiner,1992 and Ghafooret al., 2003).In the current study, the 
morphological traitsshowed much closer resemblance among populations of A. santolinacompared to ISSR polymorphism as reflected by the distance on the trees distance scales. Whereas the nine populations were divided at a distance of 15.7 in the tree based on morphological traits, the populations were divided at a distance of 62.1 on the scale of tree based on the analysis of ISSR polymorphism.

Unique ISSR markers may act as markers for discrimination among populations or accession and may be identifier for their authentication (Salimet. al., 2010). A noteworthy observation is that population S1, which has much higher number of unique bands and much lower polymorphism, was slightly morphologically distinct from other populations contrary to the substantial variation among this population and others in the ISSR fingerprinting. This variation is associated with the number of florets in the head and weigh of 100 seeds. In the two trees based on ISSR data alone and on morphological variation, the population $\mathrm{S} 1$ was also differentiated from other populations except S8 and S9.

In conclusion,morphological variation and ISSR polymorphism clearly differentiated the two populations growing in sites closer to Alexandria from populations growing further west. ISSR data also distinguished S1 that grow far west of Matrouh City. This may support a hypothesis of possible gene flow in populations of $A$. santolinagrowing in close sites in and surrounding MatrouhCity i.e. S1, S2, and S4 and S5 and limited gene flow among populations distributed in geographically distant populations i.e. S1 and S8 and S9.The knowledge of genetic variability is useful for the assessment of plant genetic resources in Egypt and provides information for conservation of $A$. santolina in the study area.

\section{Acknowledgment}

The authors are grateful to the Science and Technology Development Fund (STDF) of Egypt for supporting the research work of this article through funding the Project ID 4218 on Development of reference genetic fingerprints, preservation of germplasm and biotechnology-based production of pharmaceutically bioactive substances of some threatened Egyptian medicinal plants.

\section{References}


Aboutabl, E.A., Soliman, F.M., El-Zalabani, S., Brunke, E.J. and ElKersh, T.A. (1986). Essential oil of Achilleafragrantissima (Forssk.)Sch. Bip.ScientiaPharmaceutica. 54: 37-41.

Al-Hindawi, M.K., Al-Deen, I.H., Nabi, M.H. and Ismail, M.A. (1989). Anti-inflammatory activity of some Iraqi plants using intact rats. J.Ethnopharm.26: 163-168.

Ayala, F. (1982).Genetic variation in natural populations: Problem of electrophoretically cryptic alleles. Proc. Natl. Acad. Sci. 79: 550-554

Badr, A. (2008). Molecular approaches in plant systematics and evolution. Taeckholmia28: 127-167.

Badr A., H.H. El-Shazly and M.M.Sakr (2014).Role of biotechnology in conservation and sustainable use of medicinal plants in the arid regions. In Govil JN (Chief ed.).Recent Progress in Medicinal PlantsVol. 39: Biotechnology and Genetic Engineering. Kumar PA (Volume ed.) Studium Press, India and USA, pp 317-333.

Badr, A., El-Shazly, H.H., Helail, N.S., El-Ghanim, W. (2012). Genetic Diversity of Artemisia populations in central and north of Saudi Arabia based on morphological variation and RAPD polymorphism. Pl. Syst. Evol.298: 871-886.

Beuselinck, R., and Steiner, J.J. (1992).A proposed framework for identifying and utilizing plant germplasm resources.Field Crop Res. 29: 261-272.

Boulos, L. (2002).Flora of Egypt, vol. 3 (Verbenaceae - Compositae).Al Hadara Publishing, Cairo, Egypt..

Bretting, P. and Wilrlechner, M. (1995).Genetic markers and plant genetic resources management.Pl. Breed.Rev.13:11-86.

Dogan, B., Duran, A. and Hakki, E.E. (2007). Phylogenetic analysis of Jurinea (Asteraceae) species from Turkey based on ISSR amplification. Ann. Bot.Fenn.44:353-358.

El-Shazly, A.M., Hafez, S.S. and Wink, M. (2004).Comparative study of the essential oils and extracts of Achilleafragrantissima (Forssk.) Sch. Bip. andAchilleasantolina L. (Asteraceae) from Egypt. Pharmazie59:226-30.

Farajpour, M., Ebrahimi, M., Amiri, R., Ahmadm S. and Golzari, R. (2011).Investigation of variations of the essential oil content and morphological values in yarrow (Achilleasantolina) from Iran.J. Med. Pl. Res.17: 4393-4395. 
Fracaro, F., Zacaria, J, and Echeverrigaray, S, (2005). RAPD based genetic relationships between populations of three chemotypes of CunilagalioidesBenth. Bioch.System. Ecol.33: 409-417.

Ghafoor, A., Ahmad, Z., Hashmi, N.I. and Bashir, M. (2003). Genetic diversity based on agronomic traits and SDS-PAGE markers in relation to geographic pattern of blackgram [Vignamungo (L.) Hepper.J. Genet. Breed.57: 5 -11.

Hamrick, J. and Godt, H. (1996).Conservation genetics of endemic plant species. In. Avise J.C. and Hamrick, J.L. (eds.)Conservation genetics: case studies from nature: pp 281-304.Chapman and Hall. New York. USA.

Kalpana J, Warude PC, Bhushan P. (2004) Molecular markers in herbal drug technology.Curr. Sci.87(2): 159-165.

KapelanGmbHCoBio-Imaging GmbH.,available on line at www.labimage.cominfo@labimage.com.

Karp A, Isaac P, Ingram D. (1998). Molecular tools for screening biodiversity. Chapman and Hall, London.

Karp A, Seberg O, Buiatti M. (1996). Molecular techniques in the assessment of botanical diversity.Ann. Bot.78:143-149.

Legendre, L. and Legendre, P. (1983).Numerical Ecology. Elsevier Scientific Publishing Company, Amsterdam, 419 pp.

Lombard V,Dubreuil P, Dillman C, Baril C.(2001). Genetic distance estimators based on molecular data for plant registration and protection: A review. Acta Hort.546: 55-63.

Manica-Cattani. M.F., Zacaria, J., Pauletti, G., Atti-Serafini, L. and Echeverrigaray, S. (2009). Genetic variation among South Brazilian accessions of Lippiaalba Mill. (Verbenaceae) detected by ISSR and RAPD markers. Braz. J. Biol.69: 375-380.

Mohsen, H. and Ali, F. (2008).Study of genetic polymorphism of Artemisia herba-alba from Tunisia using ISSR markers.Afr. J. Biotech.7 (1): 044-050,

Morsy, A.A. (2007).Molecular variations of Achilleafragranissima (Forssk.) SCH. BIP. growing in five areas of South Sinai. Int. J. Agri. Biol.9: 11-17.

Nan, P., Peng, S., Shi, S. and Ren, H. (2003).Interpopulation congruence in Chinese Primulaovalifolia revealed by chemical and molecular markers using essential oils and ISSRs.Zeitsch.Naturf.58: 57-61. 
Rahimmalek, M., SayedTabatabaei, B.E., Arzani, A. and Etemadi, B.E. (2009). Assessment of genetic diversity among and within Achillea species using amplified fragment length polymorphism (AFLP). Bioch.Sys. Ecol.37: 354-361.

Richard, S. and Peter, H. (2007). Community Analysis Package 4.0.Searching for structure in community data. Printed: November 2007 in Lymington, UK.

Salim, K., Khanda, J.M. and Malik, Z.A. (2010). Development of RAPD markers for authentication of medicinal plantCuscutareflexa. EurAsian J.Biosci.4: 1-7.

Sarkhosh, A., Zamani, Z., Fatahi, R., and Ranjbar, H. (2009). Evaluation of genetic diversity among Iranian soft-seed pomegranate accessions by fruit characteristics and RAPD markers. ScientiaHorticulturae 121: 313-319.

Tharachand, C., Immanuel S.C., and Mythili, M.N. (2012).Molecular markers in characterization of medicinal plants: An overview. Res. Pl. Biol.2(2): 01-12.

Torre, A., Lopez, S., Yglesias, E. and Cornelius, J.P. (2008).Genetic (AFLP) diversity of nine Cedrelaodorata populations in Madre de Dios, southern Peruvian Amazon.Forest Ecol. Manag.255: 334-339.

Wallner, E., Weising, K., Rompf, R and Kahl, G. (1996). Oligonucleotide fingerprinting and RAPD analysis of Achilleaspecies: characterization and long-term monitoring of micro-propagated clones. Pl. Cell Rep.15: 647-652.

Ward, J.H. (1963).Hierarchical grouping to optimize an objective function.J. Amer. Stat.Assoc.58: 236-244.

Zietkiewicz, E., Rafalski, A. and Labuda, D. (1994).Genome fingerprinting by simple sequence repeat (SSR)-anchored polymerase chain reaction amplification.Genomics 20:176-183. 
Table 1. Site from which the examined populations of A. santolinawere collected, their GPSlocations and elevation above sea level

\begin{tabular}{|c|l|c|c|}
\hline Code & \multicolumn{1}{|c|}{ Site } & GPS location & $\begin{array}{c}\text { Elevation } \\
(\mathbf{m})\end{array}$ \\
\hline S1 & $\begin{array}{l}\text { Sidi-Barany (140 Km west of Matrouh City, 2 } \\
\text { km from the Mediterranean Coast }\end{array}$ & $\begin{array}{l}31^{\circ} 27^{\prime} 16.10^{\prime \prime} \mathrm{N} \\
26^{\circ} 25^{\prime} 58.40^{\prime \prime} \mathrm{E}\end{array}$ & 58 \\
\hline S2 & $\begin{array}{l}\text { The International Coastal Road, (50 Km west } \\
\text { of Matrouh City, 7 Km from the Mediterranean } \\
\text { Coast }\end{array}$ & $\begin{array}{l}31^{\circ} 22^{\prime} 06.60^{\prime \prime} \mathrm{N} \\
26^{\circ} 42^{\prime} 28.30^{\prime \prime} \mathrm{E}\end{array}$ & 125 \\
\hline S3 & $\begin{array}{l}\text { El-Nigela (40 Km West of Matrouh City; about } \\
\text { 450 m from the Mediterranean Coast }\end{array}$ & $\begin{array}{l}31^{\circ} 25^{\prime} 35.40^{\prime \prime} \mathrm{N} \\
26^{\circ} 43^{\prime} 39.70^{\prime \prime} \mathrm{E}\end{array}$ & 79 \\
\hline S4 & $\begin{array}{l}\text { El-Nigela (Al-MathanyRegion; close to the } \\
\text { Mediterranean Coast }\end{array}$ & $\begin{array}{l}31^{\circ} 28^{\prime} 53.00^{\prime \prime} \mathrm{N} \\
26^{\circ} 43^{\prime} 40.70^{\prime \prime} \mathrm{E}\end{array}$ & 4 \\
\hline S5 & $\begin{array}{l}\text { Matrouh City (El-Obeiyed) } \\
\text { Near the Mediterranean Coast }\end{array}$ & $\begin{array}{l}31^{\circ} 22^{\prime} 37.10^{\prime \prime} \mathrm{N} \\
27^{\circ} 04^{\prime} 22.50^{\prime \prime} \mathrm{E}\end{array}$ & 5 \\
\hline S6 & $\begin{array}{l}\text { Samala (10 Km East of Matrouh City), about } \\
\text { 500 m from the Mediterranean Coast }\end{array}$ & $\begin{array}{l}31^{\circ} 18^{\prime} 26.00^{\prime \prime} \mathrm{N} \\
27^{\circ} 17^{\prime} 19.00^{\prime \prime} \mathrm{E}\end{array}$ & 29 \\
\hline S7 & $\begin{array}{l}\text { Raas-Elhekma (57 Km East of Matrouh City), } \\
\text { Near the Mediterranean Coast }\end{array}$ & $\begin{array}{l}31^{\circ} 06^{\prime} 08.66^{\prime \prime} \mathrm{N} \\
27^{\circ} 48^{\prime} 53.00^{\prime \prime} \mathrm{E}\end{array}$ & 108 \\
\hline S8 & $\begin{array}{l}\text { El-Hammam, 65 km West of Alexandria } \\
\text { (about 10 km from the sea coast) }\end{array}$ & $\begin{array}{l}30^{\circ} 53^{\prime} 37.83^{\prime \prime} \mathrm{N} \\
29^{\circ} 33^{\prime} 16.93^{\prime \prime} \mathrm{E}\end{array}$ & 24 \\
\hline S9 & $\begin{array}{l}\text { Burg El-Arab, 40 km West of Alexandria } \\
\text { (about 10 km from the sea coast), on the edges } \\
\text { of a saline depression }\end{array}$ & $\begin{array}{l}30^{\circ} 55^{\prime} 16.25^{\prime \prime} \mathrm{N} \\
29^{\circ} 33^{\prime} 08.01^{\prime \prime} \mathrm{E}\end{array}$ & 9 \\
\hline
\end{tabular}


Table 2. List of the ISSR primers; their ID, sequences and annealing temperature and the number of polymorphic bands and percentage of polymorphism revealed by each primer in the examined populations of A. santolina.

\begin{tabular}{|c|l|l|c|c|c|c|}
\hline Ser & \multicolumn{1}{|c|}{ ID } & \multicolumn{1}{|c|}{ Sequence $\left(\mathbf{5}^{\prime} \rightarrow \mathbf{3}^{\prime}\right)$} & $\begin{array}{c}\text { Annealing } \\
\text { temperature } \\
\left.\text { Tm } \mathbf{(}^{\circ} \mathbf{C}\right)\end{array}$ & $\begin{array}{c}\text { No. Total } \\
\text { \&polymorphic } \\
\text { bands }\end{array}$ & $\begin{array}{c}\text { Polymorphism } \\
\text { percentage } \\
(\mathbf{\%})\end{array}$ \\
\hline 01 & 808 & AGAGAGAGAGAGAGAGC & 59 & 10 & 9 & 90.0 \\
\hline 02 & 813 & CTCTCTCTCTCTCTCTT & 53 & - & - & - \\
\hline 03 & 816 & CACACACACACACACAT & 54 & - & - & - \\
\hline 04 & 826 & ACACACACACACACACC & 62 & 8 & 4 & 50.0 \\
\hline 05 & 827 & ACACACACACACACACG & 62 & - & - & - \\
\hline 06 & 829 & TGTGTGTGTGTGTGTGC & 62 & - & - & - \\
\hline 07 & 17898 B & CACACACACACAGT & 42 & 7 & 4 & 57.0 \\
\hline 08 & 17899 A & CACACACACACAAC & 42 & 6 & 3 & 50.0 \\
\hline 09 & 17899 B & CACACACACACAGG & 44 & 6 & 4 & 66.7 \\
\hline 10 & HB-08 & GAGAGAGAGAGAGG & 44 & 10 & 6 & 60.0 \\
\hline 11 & HB-09 & GTGTGTGTGTGTGG & 44 & 8 & 4 & 50.0 \\
\hline 12 & HB-10 & GAGAGAGAGAGACG & 44 & 9 & 3 & 33.3 \\
\hline 13 & HB-11 & GTGTGTGTGTGTCG & 44 & 11 & 4 & 36.4 \\
\hline 14 & HB-12 & CACCACCACGC & 38 & 8 & 4 & 50.0 \\
\hline 15 & HB-13 & GAG GAGGAG GC & 38 & 6 & 4 & 66.7 \\
\hline 16 & HB-14 & CTCCTCCTCGC & 38 & 8 & 5 & 62.5 \\
\hline 17 & HB-15 & GTG GTGGTG GC & 57 & 8 & 4 & 50.0 \\
\hline Total & & & & 105 & 58 & 55.2 \\
\hline
\end{tabular}




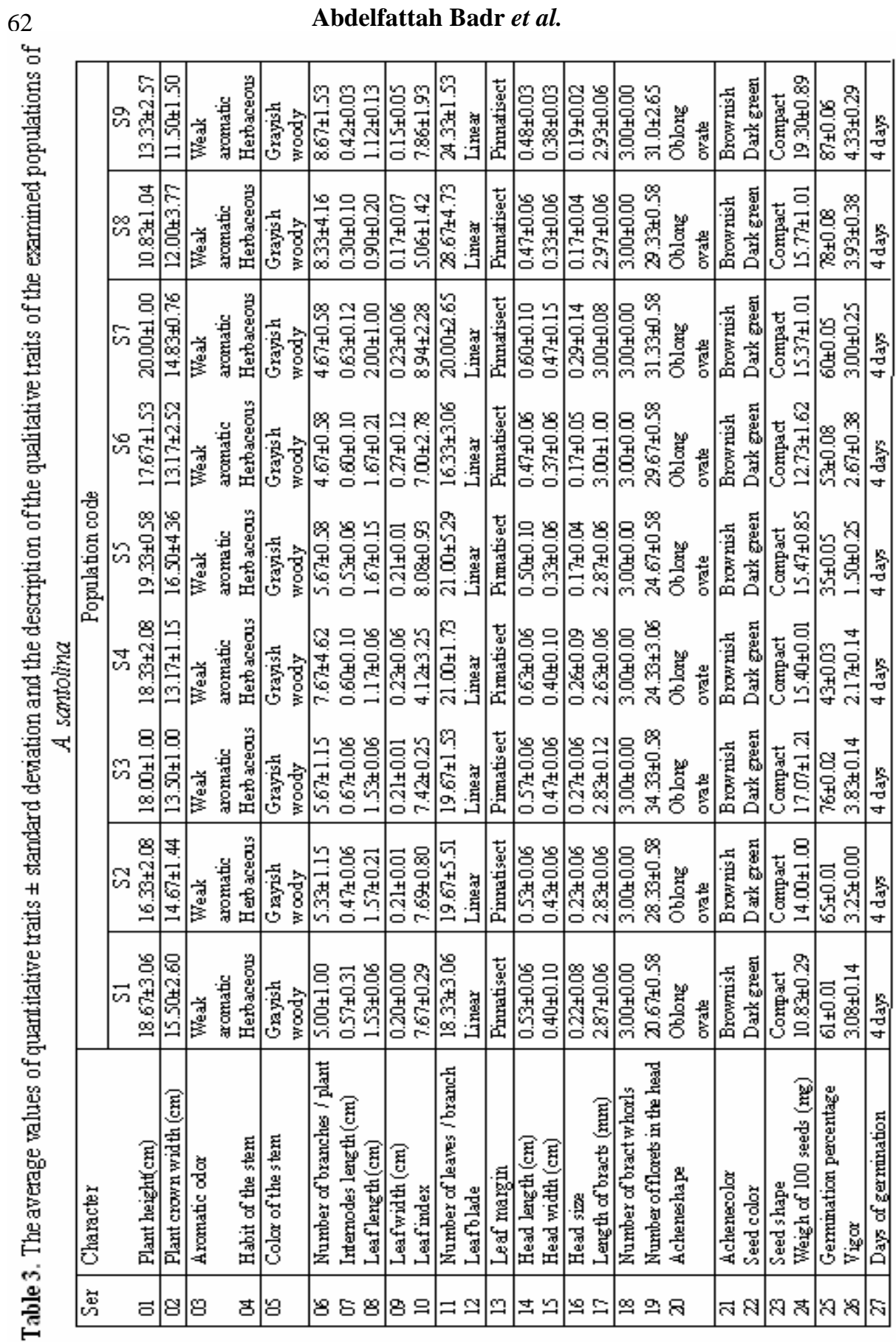




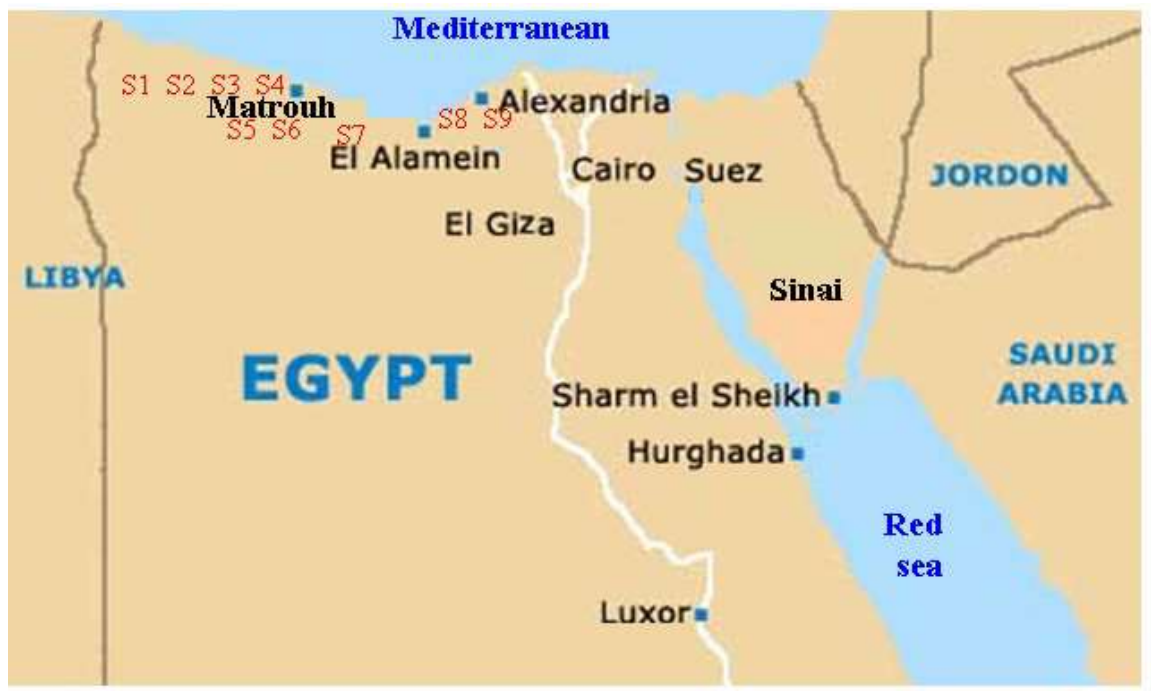

Figure 1. Map of Egypt illustrating the areas and the sites of collection of the studied populations of $A$. santolina (S1-S9) in the western Mediterranean coast of Egypt.

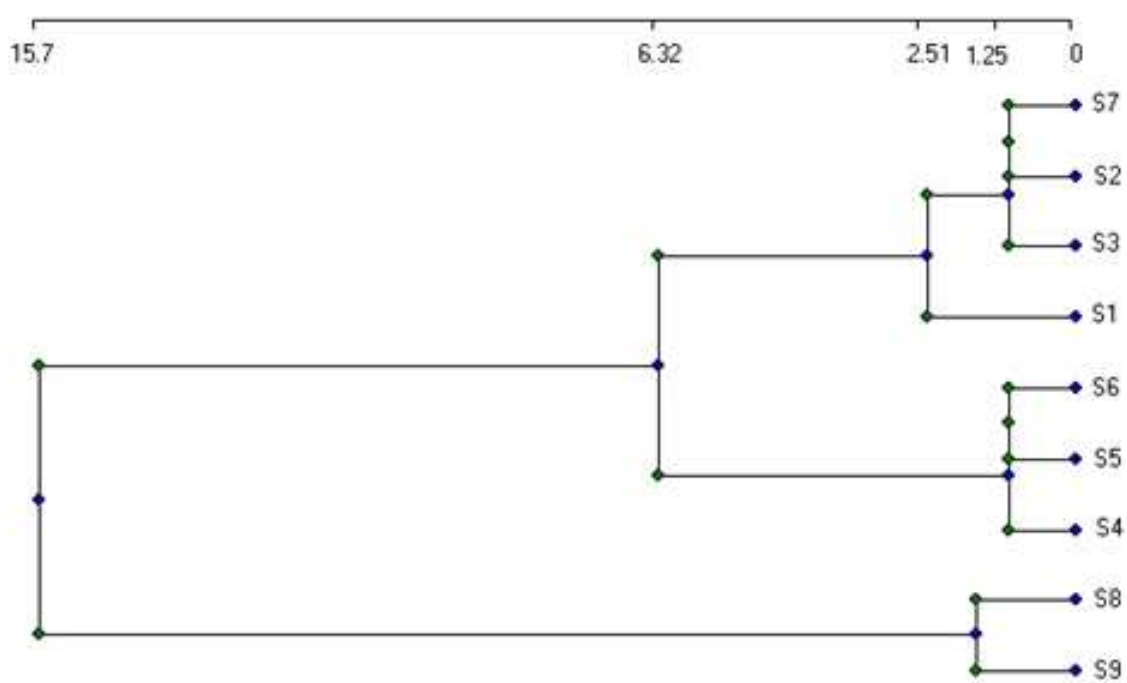

Figure 2. A Ward tree illustrating the relationships among populations of $A$. santolina (S1-S9), based on the analysis of morphological traits using the CAP software. 

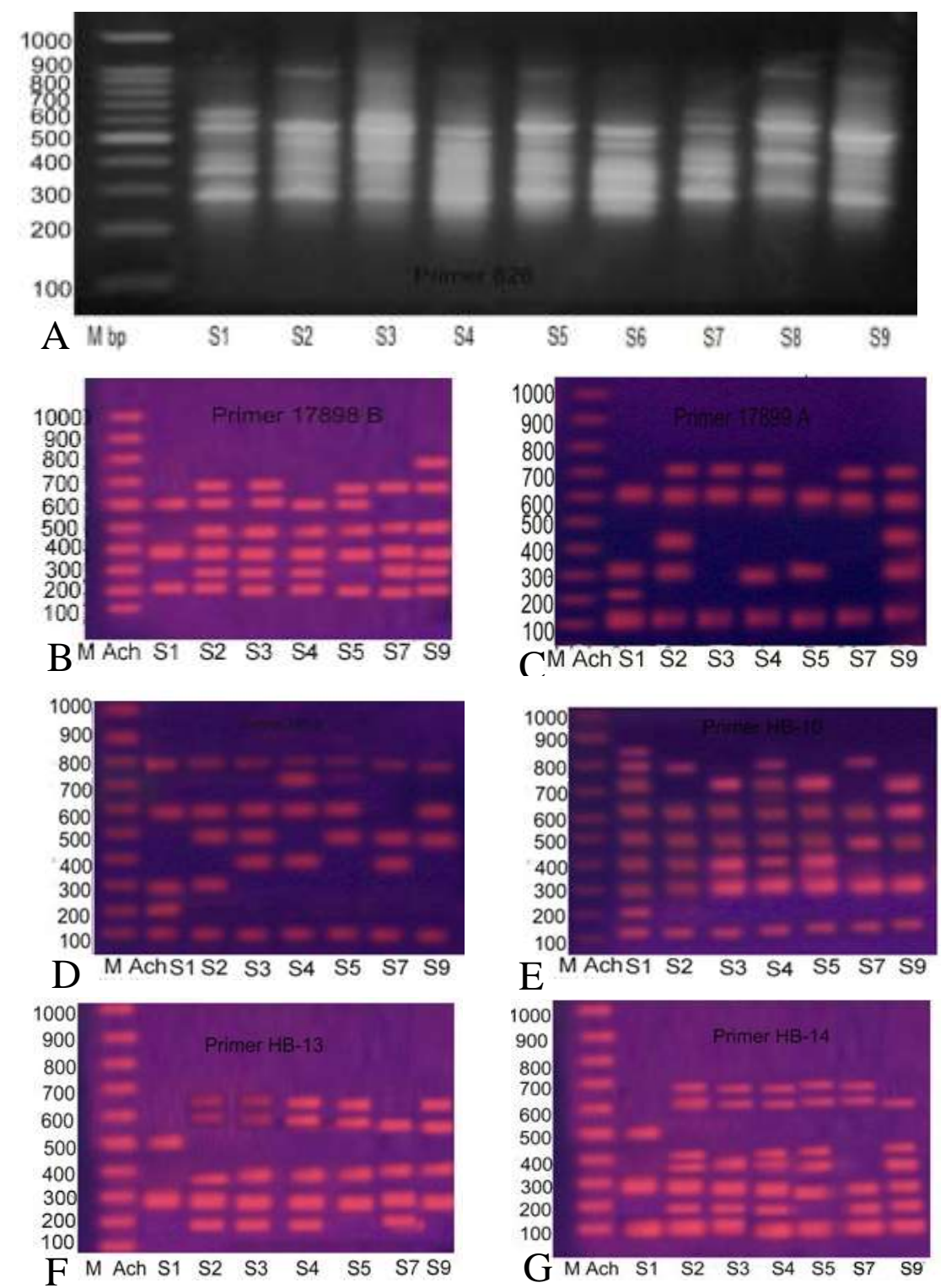

Figure 3. ISSR fingerprinting profile produced by primer 826 (in the nine examined populations of $A$. santolina and by six primers (17898B, 17899A, HB 9, HB 10, HB 13 and HB14) in seven populations of A. santolina. Population 1 showed abundance of unique bands by five primers (See arrows) 


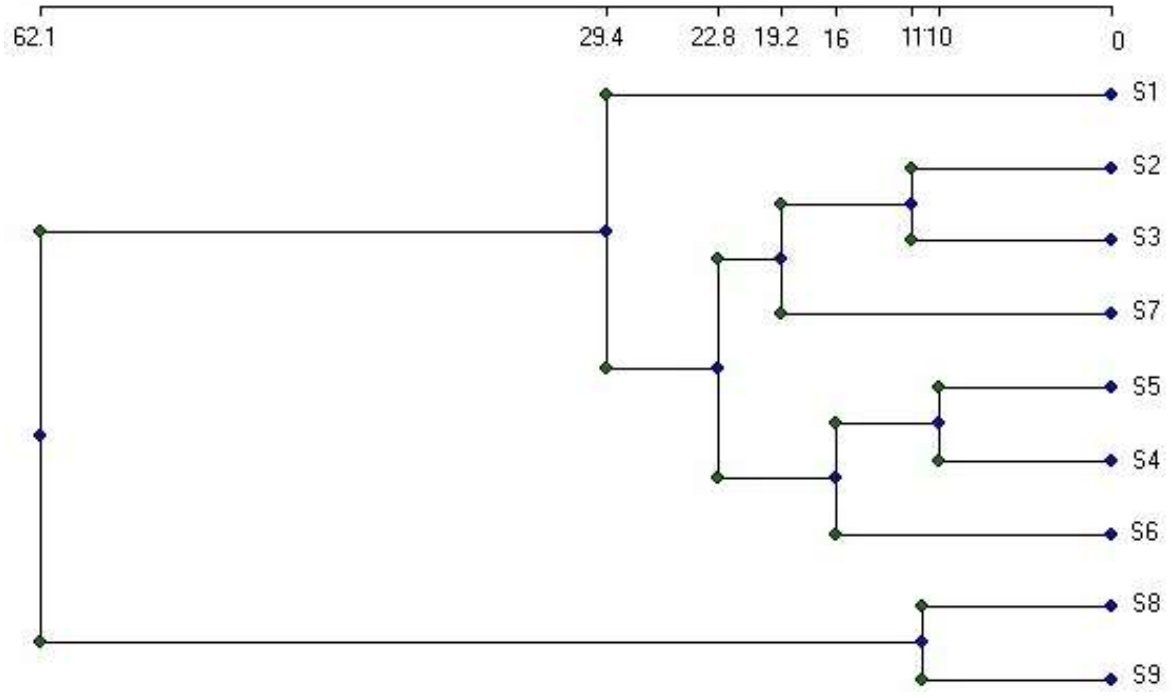

Figure 4. A Ward tree illustrating the relationships among populations of $A$. santolina (S1-S9), based on the analysis of ISSR fingerprinting using the CAP software. 